TUBERCULOSIS

\title{
Tuberculin response in BCG vaccinated schoolchildren and the estimation of annual risk of infection in Hong Kong
}

\author{
C C Leung, W W Yew, C M Tam, C K Chan, K C Chang, W S Law, S N Lee, M Y Wong, K F Au
}

Thorax 2005;60:124-129. doi: 10.1136/thx.2003.017970

See end of article for authors' affiliations

......................

Correspondence to: $\operatorname{Dr}$ C C Leung, Shaukiwan Jockey Club Clinic, 8 Chaiwan Road, Shaukiwan, Hong Kong, China; cc_leung@dh.gov. hk

Received 27 October 2003 Accepted 8 April 2004

\begin{abstract}
Background: In Hong Kong there has been nearly universal neonatal BCG vaccination coverage since 1980.

Method: 21113 schoolchildren aged 6-9 years were skin tested with one unit of tuberculin (PPD RT-23) using the intradermal technique during a routine BCG revaccination programme. Information on sex, date of birth, date of tuberculin testing, and tuberculin reaction size at 72 hours was retrieved. The annual risk of tuberculous infection (ARTI) was estimated by three different approaches.

Results: Significantly higher tuberculin positive rates were found in girls and with increasing age at all commonly used cut-off points $(5,10$, and $15 \mathrm{~mm})$. Using a cut-off point of $\geqslant 10 \mathrm{~mm}$ and the formula $1-$ $(1 \text { - tuberculin positive rate })^{1 / \text { age }}$, the ARTI was estimated to be $1.93 \%(95 \% \mathrm{Cl} 1.84$ to 2.03$)$ for girls and $1.41 \%$ (95\% Cl 1.33 to 1.50 ) for boys. Using the differences in the tuberculin positive rate between the 67 year and 8-9 year age groups, the ARTI became $1.90 \%(95 \% \mathrm{Cl} 1.09$ to 2.70$)$ and $1.84 \%(95 \% \mathrm{Cl} 1.15$ to 2.54 ) for girls and boys, respectively. When the prevalence of infection was estimated by locating a secondary peak of the tuberculin reaction distribution curve at $15 \mathrm{~mm}$ and assuming a symmetrical distribution of reaction sizes among those infected around this peak, the corresponding ARTI was much lower at $0.52 \%(95 \% \mathrm{Cl} 0.46$ to 0.59$)$ and $0.43 \%(95 \% \mathrm{Cl} 0.37$ to 0.49$)$ for girls and boys, similar to that estimated indirectly from the prevalence of disease.

Conclusion: The ARTI as estimated by conventional methods was unexpectedly high among BCG vaccinated children and did not agree with that anticipated from the annual incidence of active disease. Further studies are needed to address the discrepancies, including the possible interaction between BCG and other environmental stimuli.
\end{abstract}

I Hong Kong the notification rate of tuberculosis (TB) decreased from a peak of 697.2 per 100000 in 1952 to 113.7 per 100000 in $2000 .^{1}$ The coverage of neonatal BCG vaccination has been persistently around $99 \%$ since $1980 .^{1}$ Those not vaccinated are not only too few in number, but are also likely to be a highly selected and non-representative group. As a result, there has been no systematic use of tuberculin surveys to estimate the annual risk of tuberculous infection (ARTI) in Hong Kong to date. ${ }^{2}$

In a BCG vaccinated cohort the tuberculin reaction is influenced by waning tuberculin reactivity from neonatal BCG vaccination, atypical mycobacterial infection, and Mycobacterium tuberculosis infection. The former two are expected to cause a less strong reaction, generally $<15 \mathrm{~mm}^{3}{ }^{4}$ On the other hand, TB infection is likely to cause a much stronger reaction with a peak around $15 \mathrm{~mm} .^{3}{ }^{4}$ In a series of studies done in Hong Kong in conjunction with the regional TB adviser of the World Health Organization in 1967, the mean (SD) tuberculin response to one unit of PPD RT-23 among bacteriologically confirmed TB cases was 18.5 (3.3) $\mathrm{mm}$ and that for BCG vaccinated infants 3 months after vaccination was $4.0(3.2) \mathrm{mm}^{5}$

In any area practising neonatal BCG vaccination, the interaction of BCG with the tuberculin response is crucial in the diagnosis and treatment of latent TB infection. In day to day clinical practices, 5, 10, $15 \mathrm{~mm}$ are the three cutoff points that have been commonly recommended for diagnosis of tuberculosis infection under different settings. ${ }^{6}$ The $10 \mathrm{~mm}$ cut-off point is the one most commonly used, except in situations where the likely prevalence of TB infection or its consequential risk is very high. ${ }^{6}$ Partly as a result of widespread neonatal BCG vaccination, the $10 \mathrm{~mm}$ cut-off point has been consistently used in Hong Kong. ${ }^{7}$
There have been few published data in relation to the other cut-off points. This study examined the effects of sex and age on the tuberculin reaction profile among primary school children aged 6-9 years in Hong Kong, and investigated whether there are plausible ways of estimating the ARTI.

\section{METHODS}

Revaccination after tuberculin testing was widely practised in Hong Kong until 2000. From October 1999 to February 2000, routine BCG revaccination was carried out in a total of 40 consecutive primary schools in Hong Kong. With consent from the parents, $95 \%$ of children from primary classes 1 to 4 were skin tested before revaccination with one unit of tuberculin (PPD RT-23) on the left forearm by a team of inoculators from the $\mathrm{TB}$ and Chest Service using the intradermal technique. The maximum transverse diameter of the induration was measured with a ruler after 72 hours. The neonatal BCG vaccination status and scar were not checked in view of almost universal neonatal BCG vaccination. All participating children aged $6-9$ years $(<10$ years $)$ were included in this study.

The name, sex, date of birth, date of tuberculin testing, and exact tuberculin reaction size at 72 hours of all study subjects were entered into a spreadsheet and then imported into a statistical package (SPSS Version 10) for analysis. The tuberculin positive rates at the cut-off points of 5,10 , $15 \mathrm{~mm}$ for the different sexes and ages were derived and compared using $\chi^{2}$ statistics. A multiple logistic regression model involving sex and age and a constant was then used to assess the independent effect of sex and age on the positive tuberculin response at different cut-off points. A p value of $<0.05$ was taken as statistically significant. 


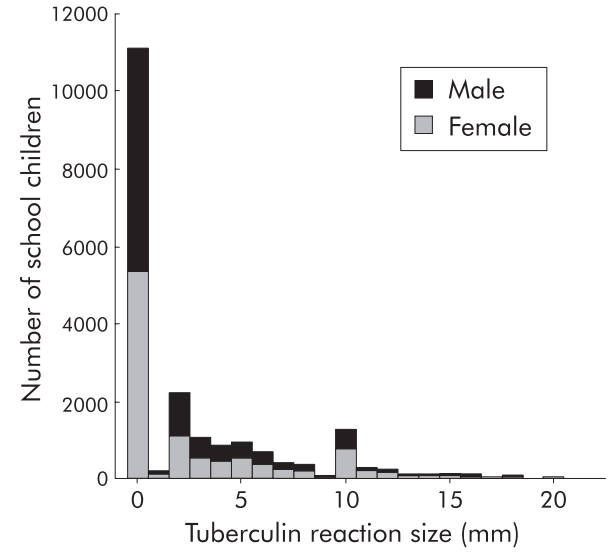

Figure 1 Tuberculin response in girls and boys aged 6-9 years in Hong Kong.

The ARTI was estimated by three different approaches. In the first (classical) approach the annual rate of infection was estimated from the tuberculin positive rate at a cut-off point of $\geqslant 10 \mathrm{~mm}$ for those aged 6-9 years using the formula:

$$
\text { ARTI }=1-(1-P)^{1 / \text { age }}
$$

where $\mathrm{P}$ is the tuberculin positive rate at the time of testing and age is the mean age of the cohort. ${ }^{8}$ This approach assumes a constant rate of exponential decline in the proportion of uninfected individuals by a factor of (1 ARTI) per year from birth.

In an attempt to eliminate the confounding effect of neonatal BCG vaccination, the second (two cohort) approach made use of the difference in the tuberculin positive rates and mean ages between two cohorts of different ages. Assuming an exponential decline in the proportion of uninfected individuals between the age of the younger cohort $\left(a_{1} e_{1}\right)$ and the older cohort $\left(\mathrm{age}_{2}\right)$ by a factor of $(1-$ ARTI) per year, it can easily be shown that the uninfected proportion at age $_{2}=$ the uninfected proportion at age $\mathrm{a}_{1} \times$ $(1-\text { ARTI })^{\text {age }}{ }_{2}-{ }_{1}$ age ${ }_{1}$, or

$$
1-\mathrm{P}_{2}=\left(1-\mathrm{P}_{1}\right) \times(1-\mathrm{ARTI})^{\mathrm{age}_{2}-\mathrm{age}_{1}}
$$

where $\mathrm{P}_{1}$ and $\mathrm{P}_{2}$ are the tuberculin positive rates of the first and second (older) cohorts, and age $\mathrm{e}_{1}$ and age $\mathrm{e}_{2}$ are their mean ages, respectively. On rearranging the terms, the final formula is therefore as follows:

$$
\text { ARTI }=1-\left[1-\left(\mathrm{P}_{2}-\mathrm{P}_{1}\right) /\left(1-\mathrm{P}_{1}\right)\right]^{1 /\left(\mathrm{age}_{2}-\mathrm{age}_{1}\right)}
$$

The third (secondary peak) approach assumed a symmetrical distribution of tuberculin test reaction sizes among those infected with TB with a peak at or around $15 \mathrm{~mm}$, and the proportion of infected individuals was estimated by the location of the mode and the right side arm of distribution using a method similar to that depicted by the American Thoracic Society statement on tuberculin skin testing in 1981. ${ }^{9}$ From this proportion the ARTI was estimated using the same formula as the first approach.

The ARTI derived by the above three approaches was also compared with that estimated indirectly from the annual incidence of disease according to the commonly adopted equation: ARTI (\%) $\times \mathrm{S}=$ incidence of sputum smear positive cases per 100000 person-years, where $S$ is the empirically derived ratio of smear positive incidence to percentage ARI and has previously been estimated to be $50 .^{21011}$

\section{RESULTS}

A total of 21113 schoolchildren aged 6-9 years were tuberculin tested between October 1999 and February 2000. The exact magnitude of the tuberculin response or date of birth was not known for 291, leaving 20822 schoolchildren for analysis. The mean (SE) age was 8.04 (0.01) years. Figure 1 shows the distribution of the tuberculin reaction with respect to sex. Despite some suggestion of digit preference, the overall patterns were very similar between the two sexes. The mean (SE) tuberculin reaction size was $2.85(0.03) \mathrm{mm}$ overall, and was significantly higher in girls than in boys $(3.13(0.04) \mathrm{mm} v 2.55(0.04) \mathrm{mm}, \mathrm{p}<0.001)$. The mean (SE) reaction size for those tuberculin positive at

\begin{tabular}{|c|c|c|c|c|c|c|c|c|}
\hline \multirow[b]{2}{*}{ Sex } & \multirow[b]{2}{*}{ Age } & \multirow[b]{2}{*}{ No } & \multicolumn{6}{|c|}{ Tuberculin positive rates at different cut-off points (\%) } \\
\hline & & & $\geqslant 5 \mathrm{~mm}$ & $(95 \% \mathrm{Cl})$ & $\geqslant 10 \mathrm{~mm}$ & $(95 \% \mathrm{Cl})$ & $\geqslant 15 \mathrm{~mm}$ & $(95 \% \mathrm{Cl})$ \\
\hline Girls & $\begin{array}{l}6 \\
7 \\
8 \\
9 \\
\text { All } \\
p^{*}\end{array}$ & $\begin{array}{r}2476 \\
2761 \\
2736 \\
2701 \\
10674\end{array}$ & $\begin{array}{l}24.27 \\
26.29 \\
29.68 \\
32.32 \\
28.22 \\
<0.001\end{array}$ & $\begin{array}{l}(22.67 \text { to } 25.96) \\
(24.65 \text { to } 27.94) \\
(27.97 \text { to } 31.39) \\
(30.56 \text { to } 34.09) \\
(27.36 \text { to } 29.07)\end{array}$ & $\begin{array}{l}11.59 \\
14.05 \\
15.20 \\
16.96 \\
14.51 \\
<0.001\end{array}$ & $\begin{array}{l}\text { (10.33 to } 12.85) \\
\text { (12.76 to } 15.35) \\
\text { (13.86 to } 16.55) \\
\text { (15.54 to } 18.37) \\
\text { (13.84 to } 15.18)\end{array}$ & $\begin{array}{l}1.86 \\
2.43 \\
2.60 \\
2.74 \\
2.42 \\
0.04\end{array}$ & $\begin{array}{l}(1.33 \text { to } 2.39) \\
(1.85 \text { to } 3.00) \\
\text { (2.00 to } 3.19) \\
\text { (2.12 to } 3.36) \\
(2.13 \text { to } 2.71)\end{array}$ \\
\hline Boys & $\begin{array}{l}6 \\
7 \\
8 \\
9 \\
\text { All } \\
p^{*}\end{array}$ & $\begin{array}{r}2340 \\
2539 \\
2662 \\
2607 \\
10148\end{array}$ & $\begin{array}{l}19.02 \\
19.93 \\
23.63 \\
25.58 \\
22.14 \\
<0.001\end{array}$ & $\begin{array}{l}(17.43 \text { to } 20.61) \\
(18.37 \text { to } 21.48) \\
\text { (22.01 to } 25.24) \\
(23.91 \text { to } 27.26) \\
(21.33 \text { to } 22.95)\end{array}$ & $\begin{array}{l}8.76 \\
9.49 \\
11.50 \\
13.31 \\
10.83 \\
<0.001\end{array}$ & $\begin{array}{l}\text { (7.61 to } 9.91) \\
(8.35 \text { to } 10.63) \\
(10.28 \text { to } 12.71) \\
(12.01 \text { to } 14.62) \\
(10.23 \text { to } 11.43)\end{array}$ & $\begin{array}{l}1.41 \\
1.65 \\
2.22 \\
2.72 \\
2.02 \\
<0.001\end{array}$ & $\begin{array}{l}(0.93 \text { to } 1.89) \\
(1.16 \text { to } 2.15) \\
\text { (1.66 to } 2.78) \\
\text { (2.10 to } 3.35) \\
(1.75 \text { to } 2.29)\end{array}$ \\
\hline Overall & $\begin{array}{l}6 \\
7 \\
8 \\
9 \\
\text { All } \\
p^{*}\end{array}$ & $\begin{array}{r}4816 \\
5300 \\
5398 \\
5308 \\
20822\end{array}$ & $\begin{array}{l}21.72 \\
23.25 \\
26.70 \\
29.01 \\
25.26 \\
<0.001\end{array}$ & $\begin{array}{l}(20.55 \text { to } 22.88) \\
\text { (22.11 to } 24.38) \\
\text { (25.51 to } 27.88) \\
\text { (27.79 to } 30.23) \\
\text { (24.67 to } 25.85)\end{array}$ & $\begin{array}{l}10.22 \\
11.87 \\
13.38 \\
15.17 \\
12.72 \\
<0.001\end{array}$ & $\begin{array}{l}(9.36 \text { to } 11.07) \\
(11.00 \text { to } 12.74) \\
(12.47 \text { to } 14.28) \\
(14.20 \text { to } 16.13) \\
(12.26 \text { to } 13.17)\end{array}$ & $\begin{array}{l}1.64 \\
2.06 \\
2.41 \\
2.73 \\
2.22 \\
<0.001\end{array}$ & $\begin{array}{l}(1.28 \text { to } 2.00) \\
\text { (1.67 to } 2.44) \\
\text { (2.00 to } 2.82) \\
\text { (2.29 to } 3.17) \\
\text { (2.02 to } 2.42)\end{array}$ \\
\hline
\end{tabular}
the cut-off point of $\geqslant 10 \mathrm{~mm}$ was 11.9 (0.05) $\mathrm{mm}$ with no

Table 1 Tuberculin positive rates at different cut-off points by sex and age 
Table 2 Independent predictors of tuberculin positivity at different cut-off points

\begin{tabular}{llllll}
\hline Cut-off point & Predictors & Exp(B) & $95 \% \mathrm{Cl}$ & p value & Goodness of fit* \\
\hline$\geqslant 5 \mathrm{~mm}$ & Female sex & 1.388 & 1.303 to 1.478 & $<0.001$ & 0.476 \\
& Age & 1.148 & 1.117 to 1.181 & $<0.001$ & \\
\multirow{2}{*}{$\geqslant 10 \mathrm{~mm}$} & Female sex & 1.403 & 1.292 to 1.524 & $<0.001$ & 0.895 \\
& Age & 1.169 & 1.127 to 1.212 & $<0.001$ & \\
& Female sex & 1.205 & 1.001 to 1.451 & 0.049 & 0.152 \\
& Age & 1.176 & 1.084 to 1.277 & $<0.001$ & \\
\hline \multirow{2}{*}{ *Hosmer-Lemeshow goodness of fit. } & & & &
\end{tabular}

significant difference between boys and girls (11.99 (0.08) $\mathrm{mm} v 11.83(0.07) \mathrm{mm}, \mathrm{p}=0.559)$. The mean (SE) reaction size for those tuberculin negative at the cut-off point of $\geqslant 10 \mathrm{~mm}$ was $1.53(0.02) \mathrm{mm}$ with a highly significant difference between boys and girls $(1.40(0.02) \mathrm{mm} v 1.65$ (0.02) $\mathrm{mm}, \mathrm{p}<0.001)$.

Table 1 summarises the tuberculin positive rates at different cut-off points for schoolchildren of different sexes and ages. At the cut-off point of $\geqslant 5 \mathrm{~mm}, 28.2 \%$ (95\% CI 27.4 to 29.1) of girls were tuberculin positive compared with $22.1 \%$ (95\% CI 21.3 to 23.0$)$ of boys $(\mathrm{p}<0.001)$. At the cut-off point of $\geqslant 10 \mathrm{~mm}, 14.5 \%$ (95\% CI 13.8 to 15.2 ) of girls were tuberculin positive compared with $10.8 \%$ (95\% CI 10.2 to 11.4 ) of boys $(\mathrm{p}<0.001)$. At the cut-off point of $\geqslant 15 \mathrm{~mm}$ the corresponding rates were $2.42 \%(95 \%$ CI 2.13 to 2.71 ) and $2.02 \%(95 \%$ CI 1.75 to 2.29$)$, respectively $(\mathrm{p}=0.029)$.

A significant linear trend was found between the tuberculin positive rates and age at all cut-off points which persisted when the two sexes were analysed separately (table 1). On multiple logistic regression modelling, sex and age were independent predictors of tuberculin positivity at all cut-off points (table 2).

The ARTI for both sexes was estimated by the first (classical) approach and the second (two-cohort) approach as detailed in the methodology section. The results are summarised in tables 3 and 4, respectively.

The distribution of tuberculin reaction sizes among reactors is shown in fig 1 . A small secondary peak could be located around $15 \mathrm{~mm}$. The prevalence of infection was estimated by the secondary peak approach assuming a symmetrical distribution with the peak at $15 \mathrm{~mm}$. Sensitivity of the estimation to the location of the peak was assessed by repeating the calculation with the peak placed at $15.5 \mathrm{~mm}$ and $14.5 \mathrm{~mm}$, respectively. The results are summarised in table 5. When the differences between the 67 year old and 8-9 year old cohorts were used, the ARTI was estimated at $0.68 \%$ (95\% CI 0.30 to 1.06 ), table 6 .

From 1996 to 2000 the notification rates for sputum smear positive cases ranged from 27.1 to $32.9 / 100000$ with a mean rate of $31.18 / 100000$ (95\% CI 28.24 to 34.12$).{ }^{1}$ The ARTI estimated indirectly from the incidence of disease was $0.62 \%$ (95\% CI 0.56 to 0.68 ).

\section{DISCUSSION}

In this study there were significant differences between the two sexes in the tuberculin positive rates at all cut-off points. This is in contrast to a study in an Aboriginal population of Canada that did not show any difference in the prevalence of tuberculin positivity ( $\geqslant 10 \mathrm{~mm}$ ) between the two sexes before the onset of puberty, ${ }^{12}$ and another study in Malawi which also did not show any difference in the prevalence of low grade positivity $(\geqslant 1 \mathrm{~mm}$ ) between the two sexes before puberty, both in those with and those without a BCG scar. ${ }^{13}$ The same study and other studies that included subjects after puberty showed a male predominance. ${ }^{14}{ }^{15}$ The reasons for the different results reported in these studies are unknown, but differences in age group studied, method of stratification, sample size, and possibly local epidemiology could have contributed.

The higher tuberculin positive rates among the girls in this study may have been the result of one or more of the following:

- difference in the prevalence of TB infection;

- difference in environmental exposure to non-tuberculous mycobacteria; and

- difference in initial or late response to BCG vaccine.

The first two factors were ongoing while the last factor depended on vaccination at a single time point early in life. The higher prevalence of tuberculin positivity among the girls was observed relatively early at the age of 6 , and the differential changes between the ages of 6 to 9 were similar in the two sexes (table 1). No differences between the sexes have been found in TB notification rates in children aged 0 9 years. ${ }^{1}$ In view of these factors, the possibility of a sex related difference in the immune response to BCG could not be excluded.

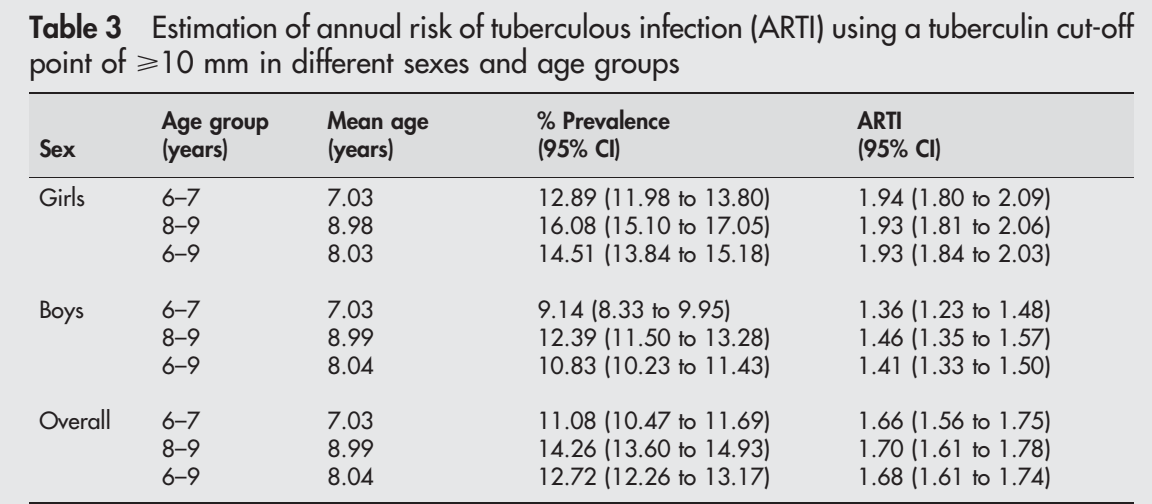


Table 4 Estimation of annual risk of tuberculous infection (ARTI) by the differences in tuberculin positive rates and mean age between two cohorts of different ages for both sexes

\begin{tabular}{|c|c|c|c|c|c|}
\hline \multirow[b]{2}{*}{ Sex } & \multicolumn{3}{|c|}{ Tuberculin positive rates (cut-off $\geqslant 10 \mathrm{~mm}$ ), $\%$} & \multirow[b]{2}{*}{$\begin{array}{l}\text { Age difference } \\
\text { (years) }\end{array}$} & \multirow[b]{2}{*}{$\begin{array}{l}\text { ARTI } \\
(95 \% \mathrm{Cl}), \%\end{array}$} \\
\hline & Age 6-7 & Age 8-9 & $\begin{array}{l}\text { Difference } \\
(95 \% \mathrm{Cl})\end{array}$ & & \\
\hline Girls & 12.89 & 16.08 & 3.19 (1.85 to 4.52$)$ & 1.95 & 1.90 (1.09 to 2.70 \\
\hline Boys & 9.14 & 12.39 & 3.25 (2.04 to 4.46$)$ & 1.96 & 1.84 (1.15 to 2.54$)$ \\
\hline Overall & 11.08 & 14.26 & 3.18 (2.27 to 4.09$)$ & 1.96 & 1.84 (1.31 to 2.37$)$ \\
\hline
\end{tabular}

Another consistent observation is the age related increase in the tuberculin response rates at all three cut-off points in both sexes (table 1). This was in sharp contrast with the reduction in the tuberculin response reported in younger children who had been vaccinated at birth. ${ }^{16}{ }^{17}$ This might suggest that the reduction in the BCG effect has either stopped or been masked by a higher rate of tuberculin conversion due to tuberculous infection/exposure to nontuberculous mycobacteria. As these children came from the same primary schools, it is reasonable to assume that they shared most of the same confounding factors and that the age related changes might provide an alternative way of estimating the prevailing annual risk of infection among BCG vaccinated children.

Although there was evidence of digital preference in the reporting of tuberculin results (fig 1), this would have been expected from routine service data. As a fixed pool of staff were employed for the tuberculin testing during the revaccination programme, the digital preference would be expected to apply equally for all groups and is therefore unlikely to affect the sex and age related trends observed in this study. These 6-9year children studied between October 1999 and February 2000 were vaccinated in 1990-4. During this period the intradermal method was the only one used for babies born in the public sector while the percutaneous method was the only one used in the private sector. There is no evidence of preferential use of either method in boys and girls which might have accounted for the observed difference in tuberculin positive rates between the two sexes. The percentage of newborns born in the public sector and vaccinated using the intradermal method increased slightly from $57.5 \%$ in 1990 to $62.6 \%$ in $1994 .{ }^{18}$ Even if it is assumed that this method might give a stronger tuberculin response, it should have differentially increased the tuberculin response among the younger subjects-the reverse of what was actually observed.

In most countries where a significant proportion of the population have received BCG vaccination, the ARTI was estimated from a minority subset without a BCG scar and/or a self-reported history of BCG vaccination. ${ }^{14}{ }^{19}$ However, there is an intrinsic risk of misclassification. In two studies in northern Malawi ${ }^{20}{ }^{21}$ blind follow up of children known to have been vaccinated as infants in child health clinics indicated that less than $60-80 \%$ had a detectable scar 34 years after receiving the vaccine. The incidence of scar formation has also been reported to be lower with the multipuncture method than the intradermal method..$^{22}$ Up to half of the neonates in Hong Kong were vaccinated by the former method and a much lower incidence of scar formation was observed with the passage of time. ${ }^{7}$ A study in India also showed that failure of formation of a BCG scar at the site of vaccination may not necessarily imply failure of immunisation because most such vaccines do elicit a positive in vitro leucocyte migration inhibition response. ${ }^{23} \mathrm{~A}$ further study in India also indicated a low sensitivity $(41.3 \%)$ and specificity $(79.5 \%)$ of the recall method when the complete immunisation status was considered ${ }^{24}$ In a place with almost universal neonatal BCG coverage like Hong Kong, other methods of estimating the ARTI have therefore to be considered.

Three different approaches have been used to estimate the ARTI in this study. The first (classic) approach did not take into account the effect of BCG vaccination and gave an ARTI of $1.41 \%$ in boys and $1.93 \%$ in girls. The second (two-cohort) approach used the age related differences in tuberculin positivity rates to estimate the ARTI (table 4). As the BCG vaccination effects of the two cohorts are expected to cancel each other out, this approach would be relatively independent of any static BCG effects. It gave an ARTI of $1.84 \%$ in the

Table 5 Estimation of annual risk of tuberculous infection (ARTI) by locating a secondary peak in the distribution curves for the tuberculin response in different sexes and age groups

\begin{tabular}{|c|c|c|c|c|c|c|c|}
\hline \multirow[b]{3}{*}{ Sex } & \multirow[b]{3}{*}{ Age } & \multicolumn{6}{|c|}{ Location of secondary peak } \\
\hline & & \multicolumn{2}{|l|}{$15 \mathrm{~mm}$} & \multicolumn{2}{|l|}{$14.5 \mathrm{~mm}$} & \multicolumn{2}{|l|}{$15.5 \mathrm{~mm}$} \\
\hline & & $\begin{array}{l}\text { \% Prevalence } \\
(95 \% \mathrm{CI})\end{array}$ & $\begin{array}{l}\% \text { ARTI } \\
(95 \% \mathrm{CI})\end{array}$ & $\begin{array}{l}\% \\
\text { Prevalence }\end{array}$ & $\begin{array}{l}\% \text { ARTI } \\
(95 \% \mathrm{Cl})\end{array}$ & $\begin{array}{l}\% \\
\text { Prevalence }\end{array}$ & $\begin{array}{l}\text { \% ARTI } \\
(95 \% \text { CI) }\end{array}$ \\
\hline Girls & $\begin{array}{l}6-7 \\
8-9 \\
6-9\end{array}$ & $\begin{array}{l}3.74(3.06 \text { to } 4.42) \\
4.49(3.77 \text { to } 5.21) \\
4.12 \text { (3.62 to } 4.62)\end{array}$ & $\begin{array}{l}0.54(0.44 \text { to } 0.64) \\
0.51(0.43 \text { to } 0.59) \\
0.52(0.46 \text { to } 0.59)\end{array}$ & $\begin{array}{l}4.32 \\
5.33 \\
4.83\end{array}$ & $\begin{array}{l}0.63(0.51 \text { to } 0.74) \\
0.61(0.51 \text { to } 0.71) \\
0.62(0.54 \text { to } 0.69)\end{array}$ & $\begin{array}{l}3.17 \\
3.64 \\
3.41\end{array}$ & $\begin{array}{l}0.46(0.36 \text { to } 0.56) \\
0.41(0.33 \text { to } 0.49) \\
0.43(0.37 \text { to } 0.49)\end{array}$ \\
\hline Boys & $\begin{array}{l}6-7 \\
8-9 \\
6-9\end{array}$ & $\begin{array}{l}2.52 \text { (1.95 to } 3.09) \\
4.23(3.51 \text { to } 4.95) \\
3.41 \text { (2.95 to } 3.87)\end{array}$ & $\begin{array}{l}0.36(0.28 \text { to } 0.45) \\
0.48(0.40 \text { to } 0.56) \\
0.43(0.37 \text { to } 0.49)\end{array}$ & $\begin{array}{l}3.07 \\
4.93 \\
4.04\end{array}$ & $\begin{array}{l}0.44(0.34 \text { to } 0.54) \\
0.56(0.46 \text { to } 0.66) \\
0.51(0.44 \text { to } 0.58)\end{array}$ & $\begin{array}{l}1.97 \\
3.53 \\
2.78\end{array}$ & $\begin{array}{l}0.28(0.20 \text { to } 0.36) \\
0.40(0.32 \text { to } 0.48) \\
0.35(0.29 \text { to } 0.41)\end{array}$ \\
\hline Overall & $\begin{array}{l}6-7 \\
8-9 \\
6-9\end{array}$ & $\begin{array}{l}3.08 \text { (2.64 to } 3.52) \\
4.36(3.85 \text { to } 4.87) \\
3.77(3.43 \text { to } 4.11)\end{array}$ & $\begin{array}{l}0.44(0.38 \text { to } 0.51) \\
0.50(0.44 \text { to } 0.55) \\
0.48(0.43 \text { to } 0.52)\end{array}$ & $\begin{array}{l}3.72 \\
5.14 \\
4.45\end{array}$ & $\begin{array}{l}0.54(0.46 \text { to } 0.61) \\
0.59(0.52 \text { to } 0.65) \\
0.56(0.51 \text { to } 0.62)\end{array}$ & $\begin{array}{l}2.45 \\
3.59 \\
3.10\end{array}$ & $\begin{array}{l}0.35(0.31 \text { to } 0.44) \\
0.41(0.35 \text { to } 0.46) \\
0.39(0.35 \text { to } 0.43)\end{array}$ \\
\hline
\end{tabular}


Table 6 Estimation of annual risk of tuberculous infection (ARTI) by differences in the estimated prevalence of infection and mean age between two cohorts of different ages

\begin{tabular}{|c|c|c|c|c|c|}
\hline \multirow[b]{2}{*}{$\begin{array}{l}\text { Secondary peak } \\
(\mathrm{mm})\end{array}$} & \multicolumn{3}{|c|}{$\%$ prevalence of infection } & \multirow[b]{2}{*}{$\begin{array}{l}\text { Difference in age } \\
\text { (years) }\end{array}$} & \multirow[b]{2}{*}{$\begin{array}{l}\% \text { ARTI } \\
(95 \% \text { CI) }\end{array}$} \\
\hline & Age 6-7 & Age 8-9 & $\begin{array}{l}\text { Difference } \\
(95 \% \mathrm{Cl})\end{array}$ & & \\
\hline $\begin{array}{l}15 \\
14.5 \\
15.5\end{array}$ & $\begin{array}{l}3.08 \\
3.72 \\
2.59\end{array}$ & $\begin{array}{l}4.36 \\
5.14 \\
3.59\end{array}$ & $\begin{array}{l}1.28(0.56 \text { to } 2.00) \\
1.42(0.62 \text { to } 2.22) \\
1.00(0.33 \text { to } 1.67)\end{array}$ & $\begin{array}{l}1.96 \\
1.96 \\
1.96\end{array}$ & $\begin{array}{l}0.68(0.30 \text { to } 1.06) \\
0.76(0.33 \text { to } 1.18) \\
0.52(0.17 \text { to } 0.88)\end{array}$ \\
\hline
\end{tabular}

boys and $1.90 \%$ in the girls. Both the classic approach and the two-cohort approach gave a relatively high ARTI, despite the fact that only one unit of RT23 was used for tuberculin testing. Even higher tuberculin positive rates and ARTI would be expected with two units of RT23. In contrast with the classic approach, the two-cohort approach gave a highly comparable ARTI between boys and girls which might be in keeping with their likely similar exposure to $M$ tuberculosis both at home and at school before the onset of puberty.

Apart from a minor difference between the sexes, these two different approaches gave largely equivalent results. If this result represents the true ARTI, this would have implied that the effect of neonatal BCG vaccination had reduced by the age of 6 years and did not affect the estimation of ARTI by the classic approach. As mentioned above, studies on tuberculin sensitivity after neonatal BCG vaccination have shown a rapid reduction in the tuberculin response with time. ${ }^{16}{ }^{17}$ A study examined 2588 randomly selected Saudi children aged 5-13 years, 1945 of whom had been vaccinated with BCG at birth and 643 were unvaccinated. ${ }^{25}$ Only $7.8 \%$ of the BCG vaccinated children were Mantoux positive ( $\geqslant 10 \mathrm{~mm}$ induration) at the age of 5 years, which was not significantly different from the unvaccinated children. A study in Canada ${ }^{26}$ suggested that, among those receiving BCG vaccination in infancy, the prevalence of tuberculin reactions of $10 \mathrm{~mm}$ was similar to the non-vaccinated subjects after an interval of 10-25 years.

In the third (secondary peak) approach a very large sample size was needed to allow identification of a small secondary peak near $15 \mathrm{~mm}$. This peak occurred at a slightly smaller induration size than those reported for patients with currently active disease when a similar test dose of RT-23 was used. ${ }^{5}$ It is uncertain whether the passage of time after infection could have accounted for this phenomenon. The actual location of a secondary peak around $15 \mathrm{~mm}$ instead of the use of an arbitrary cut-off point may also allow for variation in the strength and potency of the tuberculin employed. Although the estimation is relatively sensitive to the exact positioning of the peak response, the estimated ARTI was consistently of the order of $0.5 \%$ (table 6 ), which is in close agreement with the ARTI estimated indirectly from the incidence of sputum smear positive cases and much lower than that obtained by either the classic or two-cohort approach.

The incidence of TB among schoolchildren with different baseline tuberculin reaction sizes in this study cohort would have thrown light on this discrepancy. However, as at 30 June 2003, only three cases have been identified through the TB notification registry. This is in keeping with the generally low incidence of TB for this particular age group and no valid conclusions can be drawn from it. In a recent study on BCG vaccinated children in Singapore the cumulative incidence of TB disease during a 4 year follow up period after tuberculin testing at the age of 12 years was 65.8/100 000 for those with a tuberculin reaction of $10-14 \mathrm{~mm}$ and 363.7/100 000 for those with a reaction of $15-17 \mathrm{~mm} .{ }^{27}$ The large discrepancy in
TB rates suggests that most tuberculin reactions of $10-$ $14 \mathrm{~mm}$ in BCG vaccinated children may not represent latent TB infection.

The overall incidence of TB in 5-9 year old children in the local community was only in the region of 10/100 000. ${ }^{1} \mathrm{~A}$ much higher incidence of disease would have been expected if the annual risk of infection was close to $2 \%$. The risk of developing active disease within the first year of infection has been reported to be as high as $12.9 \% .^{28}$ Even if we take into account the possible protective effect of BCG vaccination and assume a $2 \%$ risk of developing active disease within the first year after infection and a risk of $0.5 \%$ per year from years 2 to 5, at least 50 active TB cases per 100000 person-years should have been observed.

While the possible overestimation by the classic approach can be readily explained by its failure to allow for the effect of BCG vaccination, the reason in the two-cohort approach is much less apparent. The second approach has attempted to control for the effect of BCG vaccination by comparing the tuberculin positive rates between two similar cohorts at different ages. It would have been perfect if the BCG effect remained unchanged with time. With a reduction in the BCG response it would have underestimated the ARTI. However, it would still be subject to considerable overestimation if the effect of BCG increases with age. In the study by Al-Kassimi et $a^{25}$ in Saudi children aged 5-13 years, while the tuberculin positive rate $(\geqslant 10 \mathrm{~mm})$ in the BCG vaccinated children at the age of 5 years was not significantly different from the unvaccinated children, the tuberculin sensitivity rose more steeply with age in the BCG vaccinated than in the unvaccinated children so that the difference between the two groups became statistically significant in those aged 12 and 13. Small reactions due to reduced hypersensitivity or cross reactions may also be boosted by tuberculin testing, and a larger reaction may occur on a repeat tuberculin test given within 1 week to 1 year after the initial test. ${ }^{29}$ Such a booster effect has been reported after repeated tuberculin testing in both BCG vaccinated adults ${ }^{30}$ and children ${ }^{31}$ and is correlated with Mycobacterium specific lymphoproliferation and $\gamma$-interferon responses. ${ }^{30}$ Theoretically, immunogenic stimulation by cross reacting antigens such as those of environmental mycobacteria could result in a similar phenomenon. Indeed, in a Finnish study on neonatally BCG vaccinated schoolchildren, ${ }^{32}$ there was a significant correlation between tuberculin and Mycobacterium scrofulaceum sensitin indurations ( $r=0.75,95 \%$ CI 0.72 to 0.77$)$.

While it is not possible from this study to establish definitely the role of ongoing environmental antigenic stimulation in BCG vaccinated children, the discrepancy identified between the different approaches suggests that the effect of BCG on the tuberculin response may be more complex than was previously assumed. BCG has been one of the mostly widely administered vaccines, and the tuberculin test has been widely used to guide treatment of latent TB infection. If the secondary peak approach is the correct one, over two thirds of positive tuberculin reactions (at the cut-off 
point of $\geqslant 10 \mathrm{~mm}$ ) among low risk primary school children are false positives. Should this be the case, it may be necessary to reappraise the protocol of treatment of latent TB infection in BCG vaccinated, tuberculin positive children from high incidence areas. On the other hand, if $15 \mathrm{~mm}$ is chosen as the cut-off point, infected children with a tuberculin response on the left arm of the distribution $(<15 \mathrm{~mm})$ would be missed, and this may amount to half of all those eligible for treatment. The tuberculin skin test is thus a poor indicator of infection in the presence of BCG vaccination. Newer techniques such as the $\mathrm{T}$ cell based $\gamma$ interferon assay may have a role in differentiating between the BCG effect, atypical mycobacterial infection, and $M$ tuberculosis infection in such situations, ${ }^{33}$ although their affordability and applicability in developing countries have yet to be established.

\section{Authors' affiliations}

C C Leung, C M Tam, C K Chan, K C Chang, W S Law, S N Lee,

$M$ Y Wong, K F Au, Tuberculosis Service and Chest Service, Department of Health, Hong Kong

W W Yew, Tuberculosis and Chest Unit, Grantham Hospital, Hong Kong

The authors have not received any financial support for this study or been involved with any organisations with financial interest in the subject matter.

\section{REFERENCES}

1 Department of Health. Annual Report of Tuberculosis and Chest Service for 2000. Hong Kong: Department of Health, 2001.

2 Dye C, Scheele S, Donlin P, et al. Global burden of tuberculosis: estimated incidence, prevalence, and mortality by country. WHO Global Surveillance and Monitoring Project. JAMA 1999;282:677-86.

3 American Thoracic Society. Diagnostic standards and classification of tuberculosis in adults and children. Am J Respir Crit Care Med 2000;161:1376-9.

4 Wang L, Turner MO, Elwood RK, et al. A meta-analysis of the effect of Bacille Calmette Guerin vaccination on tuberculin skin test measurements. Thorax 2002;57:804-9.

5 Department of Health. Annual Report of Tuberculosis and Chest Service for 1967, Appendices 28 and 29. Hong Kong: Department of Health, 1968.

6 Centers for Disease Control and Prevention. Targeted tuberculin testing and treatment of latent tuberculosis infection. CDC Morbidity and Mortality Weekly Report. MMWR 2000;49:RR-6.

7 Leung CC, Tam CM, Chan SL, et al. Efficacy of the BCG revaccination programme in a cohort given BCG vaccination at birth in Hong Kong. Int J Tuberc Lung Dis 2001;5:717-23.

8 Arnadottir H, Reider HL, Trebucq A, et al. Guidelines for conducting tuberculin skin test surveys in high prevalence countries. Tuberc Lung Dis 1996;77(Suppl.): 1-20.

9 American Thoracic Society. Tuberculin skin test. Am Rev Respir Dis $1981 ; 124: 356-63$
10 Sudre $P$, ten Dam G, Kochi A. Tuberculosis: a global overview of the situation today. Bull WHO 1992;70:149-59.

11 Styblo K. The relationship between the risk of tuberculosis infection and the risk of developing infectious tuberculosis. Bull int Union Tuberc 1985:60:117-9.

12 Smeja C; Brassard P. Tuberculosis infection in an Aboriginal (First Nations) population of Canada. Int J Tuberc Lung Dis 2000;4:925-30.

13 Fine PEM, Sterne JAC, Ponnighaus JM, et al. Delayed hypersensitivity, mycobaterial vaccines and protective immunity. Lancet 1994;344:1245-9.

14 Tupasi TE, Radhakrishna S, Pascual ML, et al. BCG coverage and the annual risk of tuberculosis infection over a 14-year period in the Philippines assessed from the nationwide prevalence surveys. Int J Tuberc Lung Dis 2000;4:216-22.

15 Jentoft HF, Omenaas E, Eide GE, et al. Tuberculin reactivity: prevalence and predictors in BCG-vaccinated young Norwegian adults. Respir Med 2002;96:1033-9.

16 Bozaykut A, Ipek IO, Ozkars MY, et al. Effect of BCG vaccine on tuberculin skin tests in 1-6-year-old children. Acta Paediatr 2002;91:235-8.

17 Karalliedde S, Katugaha LP, Uragoda CG. Tuberculin response of Sri Lankan children after BCG vaccination at birth. Tubercle 1987:68:33-8.

18 Department of Health. Annual Report of Tuberculosis and Chest Service for 1990, 1991, 1992, 1993, and 1994. Hong Kong: Department of Health, $1991-, 1995$.

19 Yorulmaz F, Caglar T, Erel C, et al. Prevalence and annual risk of tuberculosis infection in Edirne, Turkey. Scand J Infect Dis 2002;34:654-6.

20 Fine PE, Ponnighaus JM, Maine N. The distribution and implications of BCG scars in northern Malawi. Bull WHO 1989;67:35-42.

21 Floyd S, Ponnighaus JM, Bliss L, et al. BCG scars in northern Malawi: sensitivity and repeatability of scar reading, and factors affecting scar size. Int J Tuberc Lung Dis 2000;4:1133-42.

22 Al Jarad N, Empey DW, Duckworth G. Administration of the BCG vaccination using the multipuncture method in schoolchildren: a comparison with the intradermal method. Thorax 1999;54:762-4.

23 Rani SH, Vijayalakshmi V, Sunil K, et al. Cell mediated immunity in children with scar-failure following BCG vaccination. Indian Pediatr 1998;35:123-7.

24 Ramakrishnan R, Rao TV, Sundaramoorthy L, et al. Magnitude of recall bias in the estimation of immunization coverage and its determinants. Indian Pediatr 1999:36:881-5.

25 Al-Kassimi FA, Abdullah AK, al-Orainey 10 , et al. The significance of positive Mantoux reactions in BCG-vaccinated children. Tubercle 1991;72:101-4.

26 Menzies R, Vissandjee B. Effect of bacille Calmette-Guerin vaccination on tuberculin reactivity. Am Rev Respir Dis 1992;145:621-5.

27 Chee CB , Soh CH, Boudville IC, et al. Interpretation of the tuberculin skin test in Mycobacterium bovis BCG-vaccinated Singaporean schoolchildren. Am J Respir Crit Care Med 2001;164:958-61.

28 Ferebee, SH. Controlled chemoprophylaxis trials in tuberculosis: a general review. Adv Tuberc Res 1970;17:28-106.

29 Thompson NJ, Glassroth JL, Snider DE, et al. The booster phenomenon in serial tuberculin testing. Am Rev Respir Dis 1979;119:587-97.

30 Sepulveda RL, Ferrer X, Latrach C, et al. The influence of Calmette-Guerin bacillus immunization on the booster effect of tuberculin testing in healthy young adults. Am Rev Respir Dis 1990;142:24-8.

31 Sepulveda RL, Burr C, Ferrer X, et al. Booster effect of tuberculin testing in healthy 6-year-old school children vaccinated with Bacillus Calmette-Guerin at birth in Santiago, Chile. Pediatr Infect Dis J 1988;7:578-81

32 Tala-Heikkila M, Nurmela T, Mislienovic O, et al. Sensitivity to PPD tuberculin and $M$ scrofulaceum sensitin in schoolchildren BCG vaccinated at birth. Tuberc Lung Dis 1992;73:87-93.

33 Ewer K, Deeks J, Alvarez, et al. Comparison of T-cell-based assay with tuberculin skin test for a diagnosis of Mycobacterium tuberculosis infection in a school tuberculosis outbreak. Lancet 2003;361:1168-73. 